Estudios Románicos, Volumen 28, 2019, pp. 347-360

ISSN: 0210-491

eISSN: 1989-614X

DOI: https://doi.org/10.6018/ER/375741

\title{
ALTHÉNOPIS: \\ LA NOVELA TRIGENERACIONAL \\ DE FABRIZIA RAMONDINO
}

(Althénopis: the trigenerational

novel of Fabrizia Ramondino)

\section{María Reyes Ferrer* \\ Universidad de Murcia}

\begin{abstract}
This article is focused on the analysis of Althénopis (1981), the first novel published by the Italian writer Fabrizia Ramondino. This piece of work, partially autobiographical, is characterized by the thoroughness of description and the succession of a sequence of scenes from everyday life, all of them set in the family environment of the protagonist. In particular, we are going to study the familiar triad, formed by the grandmother, the mother and the protagonist, and how throughout daily life events, the writer reveals the relationship among them.
\end{abstract}

Keywords: Family; Mother-children relationships; Daily life; Cuisine.

Resumen: El presente artículo se centrará en el análisis de Althénopis (1981), la primera novela publicada por la escritora italiana Fabrizia Ramodino. Esta obra, parcialmente autobiográfica, se caracteriza por la minuciosidad de las descripciones y la sucesión de escenas cotidianas, todo ello ambientado en el entorno familiar de la protagonista. Concretamente, nos detendremos en el estudio de la triada familiar, compuesta por la abuela, la madre y la protagonista y cómo, a través de la cotidianidad, la escritora desvela las relaciones entre ellas.

Palabras clave: Familia; Relación Maternofilial; Cotidianidad; Cocina.

* Dirección para correspondencia: María Reyes Ferrer. Departamento de Filología Francesa, Románica, Italiana y Árabe. Facultad de Letras, Campus de La Merced. Universidad de Murcia. Calle Santo Cristo, s/n. 30001. Murcia (maria.reyes1@um.es) 


\section{Introducción}

La primera obra de Fabrizia Ramondino, Althénopis ${ }^{1}$ (1981), oscila entre distintas tipologías y enfoques narrativos, y dificulta la tarea, si fuese necesaria, de categorizarla en un subgénero novelístico determinado. Althénopis, que literalmente significa "ojo de vieja ${ }^{2 "}$ ", fluctúa entre la novela costumbrista, ensalzando los aspectos más pintorescos y locales del sur, concretamente de Nápoles y sus habitantes; la novela social, que narra el comportamiento y la decadencia de la clase media napolitana, de su propia familia, obligada a convivir con las clases más desfavorecidas de la sociedad durante el período de la postguerra; la novela autobiográfica, o más bien parcialmente autobiográfica, en la que los recuerdos de su infancia, explicados en numerosas ocasiones a través de recursos paratextuales dirigidos expresamente al lector con el fin de lograr una correcta comprensión de la narración, se entremezclan con figuraciones y ciertas licencias en la trama que colman los vacíos de su memoria o, simplemente, embellecen las ricas y minuciosas descripciones que caracterizan su obra; y, por último, la novela de aprendizaje, pues Althénopis es el pasaje de su infancia hasta su madurez: es el crecimiento y la transformación física, psicológica y moral que sufre la protagonista a medida que el tiempo avanza y establece nuevos vínculos con la realidad que la rodea. De hecho, la novela está dividida en tres partes principales, Santa Maria del Mare, La casa de los tíos y Bestelle dei Haus, que corresponden, respectivamente, con la etapa de la niñez, la adolescencia y la madurez de la protagonista, que transcurren en un ambiente familiar y decadente en el inmediato periodo de la posguerra: "[...] Althénopis is a partially first-person re-evocation of a series of lost worlds which are presented to us via a fascinating pot-pourri of umbridled poetic suggestion and conscientious, almost academic regard for authenticity" (Usher 1993: 166).

El eclecticismo de la novela no ha pasado desapercibido por quienes se interesaron por su obra, como tampoco lo ha hecho el particular uso de la lengua. La escritora alterna de manera consciente un registro elegante con otro más popular, con el objetivo de rememorar y transmitir fielmente los diferentes episodios vividos en primera persona. El registro y la lengua utilizada -en ocasiones español o francés-, así como la cuestión lingüística y la disputa entre el uso del italiano o del dialecto ${ }^{3}$, son aspectos estrechamente relacionados con su vivencia personal y que estarán presentes en toda su obra.

1 Para realizar este estudio, hemos escogido la edición traducida al castellano de Ramón F. Reboiras y Flavia Cartoni, publicada en 1989 por la editorial Alfaguara.

2 En una de las abundantes notas a pie de página que Fabrizia Ramondino intercala con el texto, la autora explica el juego de palabras etimológico con el que se nombra su ciudad y que, a su vez, da título a su obra: "El nombre de mi ciudad natal. Originariamente su nombre significaba ojo de virgen. Pero parece que los alemanes, durante la ocupación, hallándola tan embrutecida con respecto a las descripciones de Mozart [...] y de Goethe, le cambiaron el nombre por el de Althénopis que vendría a ser ojo de vieja" (Ramondino, Althénopis 1989: 20).

3 La actitud frente al uso del dialecto evidencia un notable e intencionado alejamiento de la sociedad napolitana por dos motivos principales: su educación y formación cosmopolita, que le había impedido conocer a fondo el dialecto, y el estatus burgués de la familia, que penalizaba cualquier acercamiento a las clases populares, bien fuera en las cuestiones lingüísticas como en las culturales. Especialmente severo se mostraba el padre, que transcurría largos periodos ausente del hogar y, a su vuelta, esperaba la conservación intacta de su clase social: "Las escasas apariciones, durante aquellos años, de nuestro padre eran una llamada constate a nuestros deberes de clase social. Los «mo'» y los «jamme», admitidos en presencia de la madre, delante de él se nos atoraban en la boca como albóndigas robadas en la cocina” (Ramondino, Althénopis 1989: 70). 
Napolitana de nacimiento, desde muy joven se vio obligada a realizar numerosos viajes debido al trabajo paterno y trascurrió largos períodos de tiempo en países como España, Francia o Alemania. Vivir en distintos lugares la alejó del sentimiento de pertenencia a un emplazamiento concreto, si bien siempre fue la isla española de Mallorca, donde transcurrió varios años de su infancia, un espacio de referencia y un recuerdo desde el que construye su propia identidad. Sin embargo, a pesar de volver a Nápoles a principios de los años sesenta, Ramondino no sentirá un especial vínculo con la ciudad y, por este motivo, las cuestiones lingüísticas y culturales, que ocupan un espacio relevante en su obra, aparecen representadas desde el punto de vista de una mera observadora externa4: "L'allontanamento delle scrittrici dalla loro casa e dalla città d'origine e l'incessante ricerca di un luogo in cui sentirsi a casa suscita in loro una mancanza irreparabile, che sanno non potrà mai essere colmata" (Di Rosa 2016: 23). No obstante, lejos de pensar en un posible distanciamiento con la realidad que la rodea, su observación y la descripción de los lugares y los hechos es aguda y minuciosa. Su implicación en conocer los hábitos y costumbres de la propia familia, del entorno y, en definitiva, de la realidad cotidiana es evidente y así lo demuestra en la novela.

Este interés por narrar la cotidianidad, por el ambiente familiar y el espacio del hogar es una constante en la literatura femenina italiana del Novecento, como también lo es la representación de los vínculos familiares, favoreciendo especialmente la descripción de las relaciones madre e hija ${ }^{5}$ y la reconstrucción de la genealogía femenina. A la hora de representar a la madre y la relación maternofilial en la literatura, las escritoras se han visto obligadas a afrontar una doble problemática: por un lado, la evidente falta de referentes que tratan acerca de la relación madre-hija ${ }^{6} \mathrm{y}$, por otro, el intento de romper con el imaginario patriarcal con el que se identifica a la madre:

4 En su excelso estudio acerca de Fabrizia Ramondino, Maria Ornella Marotti la incluye, temáticamente, dentro de una tradición de escritores que han utilizado la ciudad de Nápoles y su cultura como el epicentro de su narrativa. Entre estos, Marotti destaca a Matilde Serao, Eduardo De Filippo, Giuseppe Marotta, Raffaele La Capria o Luciano De Crescenzo. No obstante, la estudiosa señala como principal diferencia entre Ramondino y el resto de los escritores la visión de "extranjera" que se mantiene presente en todas sus obras: "Ramondino holds a special position among this group. None among those who have dealt with ethnicity in the Neapolitan area have placed themselves in the position of partial outsiders to the culture and the language as she consistently does throughout her works; she plays the role of observer more than participant" (Marotti 1996: 174). Además, y como Adalgisa Giorgio (2014) sostiene, la propia escritora rechaza pertenecer a la tradición de escritores napolitanos o de ser etiquetada bajo la fórmula de escritora napolitana.

$5 \quad$ Una de las primeras estudiosas en detenerse a analizar este extendido fenómeno en la literatura femenina fue Marianne Hirsch con su publicación The Mother/Daughter plot. Narrative, psychoanalysis, feminism (1989). En contexto italiano, destaca la publicación de Adalgisa Giorgio, Writing mothers and daughter (2002) que, con un enfoque internacional, examina las relaciones maternofiliales femeninas en Italia y en otros países, y los volúmenes de Laura Benedetti, Tigress in the Snow (2007), dedicado exclusivamente a los vínculos madre e hija en la literatura italiana; Saveria Chemotti, L’inchiostro bianco. Madri e figlie nella narrativa italiana contemporánea (2009) y Patrizia Sambucco, Corpi e linguaggi. Il legame figlia-madre nelle scrittrici italiane del Novecento, publicado en el 2014.

6 La filósofa Luisa Muraro ya apuntaba a que el modelo de sociedad hegemónica occidental "[...] cura l'amore tra la madre e il figlio come il suo bene più prezioso", afirmando sentir cierta envida por los hombres y la "cultura dell'amore della madre in cui sono allevati" (Muraro 1992: 13). Muraro define este factor social como la "civiltà dell'amore esclusivamente maschile per la madre", que nace de "una cultura in cui non si insegna l'amore della madre alle donne" (Muraro 1992: 12-13), y acusa una evidente falta de tratados filosóficos, religiosos o artísticos que hagan referencia al amor madre e hija. 
Per questo liberarsi dalla maternità come ruolo, per come si è realizzato storicamente e socialmente, ha significato aprire un conflitto con la maternità stessa e allora misurarsi con il 'fantasma' della madre significa, per le donne, reinterpretare la propria differenza sessuale, rompendo la continuità col modello materno codificato, per cercare nelle proprie madri la donna, rifiutando al contempo come figlie, il mimetismo cieco per instaurare una relazione di somiglianza nella differenza (Chemotti 2009: 14)

Respecto a esto último, son numerosas las escritoras que describen las difíciles y emotivas relaciones que mantienen con la madre, quien se interpone en sus recorridos vitales e inciden directamente en la construcción de su identidad (Chemotti 2009: 22). Estos vínculos maternofiliales suelen estar caracterizados por la subordinación, la identificación, la diferenciación, el conflicto, la armonía o el rechazo, pero siempre predominará la ambivalencia del amor-odio, como sucede en esta novela:

Donna e madre sono da intendersi come generazioni successive, attraversate dal furore di una sofferenza costante, fatta di odio, amore e senso di colpa, che si ripropone ad ogni giro generazionale ogni volta che la bambina diviene donna, ed il suo rapporto con la madre cambia (Brusa 2004: 9).

Ramondino recupera su particular genealogía femenina y, de manera paralela, reconstruye su proceso identitario, pues ambos están estrechamente ligados: "The grandmother- mother-daughter triad displaces the Freudian triangle of father-mother-child as the term of reference for the young girl and then adolescent searching for her identity" (Giorgio 2002: 126). El desarrollo de la protagonista, desde la infancia hasta la edad adulta, estará marcado, entre otros motivos, por la relación que mantiene con la madre y con la abuela, dos personajes antagónicos, pero de gran relevancia a lo largo de su formación. La identidad de la protagonista estará en constante negociación, entre la figura de la madre y de la abuela, y tratará de establecer "separate identities which do not simultaneously destroy the other" (Wood 1995: 233). En vista de tales premisas, en la siguiente sección nos centraremos en el análisis de las escenas cotidianas, eminentemente femeninas, y el vínculo que se establece entre la abuela, la madre y la protagonista.

\section{Los vínculos familiares y la cotidianidad}

La incursión en el detalle mínimo y la nimia descripción de las escenas cotidianas, los espacios domésticos y quienes los habitan, son algunas de las características más notables de Althénopis. Estos rasgos convergen con la manera en la que se construye la novela: la carencia de una trama estructurada ${ }^{7}$, si bien respeta el orden cronológico de

$7 \quad$ La estudiosa Sharon Wood afirma que la novela no se sostiene sobre una verdadera trama, sino sobre lo que define como la "reappropiation through memory of the colours, the sounds, and especially the places of childhood. The text as archaeology, as a mapping- out, leads to a metonymic structural narrative of detailed vignettes, fragments of stories and snatches of history combining into a kaleidoscopic, multiple vision which resists linearity and clousure" (Wood 1995: 247). 
los acontecimientos, abre paso a una narración basada en la memoria del pasado que simula, en ocasiones, la técnica del stream of consciousness. Para ello, Ramondino utiliza una prosa caracterizada por el flujo de los pensamientos y los recuerdos que dejaron una importante huella en ella. Se centra, principalmente, en la descripción humana de numerosos miembros de su familia y ofrece al lector una multitud de tipos humanos, que examina con una curiosidad casi antropológica.

En este detallado estudio de la familia, es posible observar la posición privilegiada de las mujeres y la estructura de poder matriarcal ${ }^{8}$ que sustenta el núcleo familiar. La novela comienza, deliberadamente, con el recuerdo de la abuela ${ }^{9}$, alma mater de las mujeres de su familia y de carácter singular, y se cierra con la muerte de la madre, con quien la protagonista mantiene una difícil relación, pero que será esencial en la configuración de su identidad. La abuela, una mujer enérgica y capaz de emanar luz a pesar de vestir siempre de negro y de modo austero ${ }^{10}$, se presenta como el referente primario de la protagonista y alcanza unas dimensiones épicas, que se traducen en la admiración que siente la nieta por esta, por sus formas descuidadas y atrevidas, que subvierten las reglas del mundo en el que ha sido educada, especialmente las de la madre. A la edad de siete años, la niña es dejada al cargo de la abuela, de la que aprende a estimar los pequeños placeres cotidianos y a rechazar las exigencias propias de su clase. Por el contrario, la madre se presenta como una mujer antagónica a la abuela, generalmente enferma y malhumorada, avara en alimentos y caricias, y siempre sujeta a unas estrictas reglas de conducta de clase burguesa:

Tenía la piel blanca, surcada de venas azules en las piernas y en las muñecas; su cuerpo delgado se volvía más dulce en el vientre y el pecho y, si no fuera por aquella palidez de las muñecas, sus manos parecían las de un artesano adolescente: hábiles, pero finas, dotadas de unas uñas anchas y luminosas. Pero ya por aquellos años se le podía entrever la pureza cruel del esqueleto, y el azul violento que recorría el dorso enseñaba la fatiga y la secreta pena de la sangre. Su rostro no se veía sereno o entero sino hecho de gestos fugaces, muecas y guiños. Pero ciertamente había siempre algo que contradecía su cuerpo. En realidad, ¿cómo podía estar en armonía con aquel cuerpo dulce, y en cambio enjuto y laborioso, aquel ridículo sombrero marrón que,

8 Para un detallado estudio sobre la ambigüedad del poder matriarcal en la obra de Fabrizia Ramondino, ver MAROTTI, Maria Ornella (1996): "Ethnic Matriarchy: Fabrizia Ramondino's Neapolitan World”, Maria Ornella Marotti (ed.). Italian Women Writers from the Renaissance to the Present. Revising the Canon. Pennsylvania: The Pennsylvania State University Press, 173- 186.

9 El nombre de la abuela, así como de los hermanos, del padre y de la madre, no aparecen en la novela, tratándose de una especie de despersonalización al no identificarse plenamente con ninguno de ellos. Esta estrategia también puede estar asociada con el concepto desarrollado por la filósofa feminista Rosi Braidotti, el "sujeto nómada", es decir, un sujeto que abandona la idea de estabilidad y busca identidad basada en los cambios: "Es exactamente esta continua dislocación que permite al sujeto resistir a la asimilación y a la homologación de las modalidades dominantes de representación del yo" (Cerri 2010: 3).

10 "Vestía siempre de negro, pero cuando pasaba por la plaza de Santa Maria del Mare, los colores acechaban a su alrededor como las llamas del infierno amarillos, violetas; a veces hasta rojos y verdes. No llevaba pulseras y sin embargo, parecían emanar resplandores dorados de sus muñecas. Caminaba erguida y rápida, oscilante la gran cabellera alzada: ímpetu y altivez, bajo la falda negra se perfilaba elegante la pierna hasta el muslo y el vestido era escotado en el percho enjuto, enrojecido, con un gran lazo de terciopelo deteniendo las agitadas arterias del cuello" (Ramondino, Althénopis 1989: 13). 
acabada la guerra, volvió a exhibir y que se ponía cada vez que iba a la ciudad? [...] En cierto sentido, nosotros, que a todo y a todos queríamos hermanado, sentíamos una arrogancia en aquel carmín, un distanciamiento con respecto a las otras mujeres del pueblo (Ramondino, Althénopis 1989: 63-4).

De la madre se evidencia su carácter sombrío y la fragilidad de su cuerpo, siempre sufriente y enfermo, aquejado de fuertes migrañas que la obligaban a apartarse de la vida familiar y transcurrir la mayor parte del tiempo encerrada en su habitación, en "un paréntesis" vital. Los numerosos problemas de salud que sufre parecen estar estrechamente vinculados con el momento en el que se convierte madre, cuando la relación del sujeto femenino con la vida, con lo que se define "naturaleza mineral y vegetal", se desvanece al entrar en contacto, de manera involuntaria, con la "naturaleza sangrienta, humoral y sudorosa de la cópula, de los partos, de la leche y de las grietas" (Ramondino, Althénopis 1989: 58):

Durante un curso aprendí en la escuela el significado y la utilización del paréntesis y me pareció que mamá, no sé cuándo, quizás cuando nos marchamos de la isla o quizás mucho antes, cuando ni siquiera había nacido, se había puesto entre paréntesis. Como dos paréntesis también la encerraban las paredes de aquella casa, que parecían estar hechas de tiempo: por un lado la pared del día en el que llegamos, por otro la del día en que nos marcharíamos (Ramondino, Althénopis 1989: 59).

La madre y la abuela encarnan dos personalidades, pero ambas son figuras clave en el desarrollo de la protagonista y su percepción del entorno que la rodea:

La triade nonna-madre-figlia e non il triangolo padre-madre-figlia, costituisce il termine di riferimento assoluto per la bambina e poi rappresenta la sua adolescenza: i ricordi della gioventù di chi narra si collegano con quelli appartenenti al mondo femminile della madre della madre, stabilendo così una matrilinea che si contrappone al senso della storia trasmesso dal sistema patriarcale (Chemotti 2009: 231).

Mientras que la abuela será el referente vital de la niña, la madre supondrá la privación de la identidad y la perpetuación de los valores hegemónicos, que la protagonista rechaza por sentir la exclusión del resto de personas ${ }^{11}$, entre otros motivos. No solo será la madre quien se oponga y se distancie de la abuela por sus modos exagerados y espontáneos sino todas las mujeres de su familia, que viven conforme a unas rígidas reglas sociales, como

11 En varios pasajes de la novela, la protagonista testimonia cómo la madre trataba de instruir a sus hijos en una serie de valores con el propósito de alejarlos de las clases más desfavorecidas o, simplemente, no burguesas: "No era solamente el respeto por la naturaleza incontaminada lo que la empujaba a aquella tarea de limpieza; parecía que también quisiera borrar de su presencia cualquier huella comestible, como si alrededor de aquellas sobras anidara un presagio de decadencia, un signo misterioso e inquietante. Después nos sermoneaba advirtiéndonos que no adquiriéramos el hábito del desorden y de la suciedad propias del pueblo llano. Y nuevamente, con estas palabras, se cerraba el círculo de la comunidad familiar, excluyendo a los demás, de los que éramos distintos" (Ramondino, Althénopis 1989: 68). 
madres y esposas, que las obliga a mantener un carácter contenido y adaptarse a los tiempos, tanto sociales como existenciales. La abuela, sin embargo, vive en una atemporalidad, en un "prehistoric maternal realm" como lo define Lazzaro-Weis (1993: 108), que se contrapone al tiempo de los hombres, centrados en acontecimientos más transitorios:

En cambio, la abuela pertenecía a una época en la que se había conseguido hacer coincidir la eternidad de la historia con la de la vida, tanto es así que la historia transcurría en el progreso -aunque de ello se ocupaban los hombres- y la vida eterna y de ello se ocupaban las mujeres, rezando en las cabeceras (Ramondino, Althénopis 1989: 15).

La abuela es indiferente a las exigencias sociales, a los artificios propios de su clase, a guardar las apariencias y tratar de mantener su posición. Por ello, tras la muerte del marido, gestiona sus bienes según su apetencia y conforme a sus propias normas, algo que generará el recelo de la familia. Su ímpetu será implacable y no cederá ante las peticiones de moderación del resto de las hijas e, indirectamente, de los maridos, quienes eran incapaces de imponerse ante ella:

Vivía rodeada por la indignación de las hijas, de las restantes mujeres de su familia y por la de sus maridos, aunque en su corazón se alegraran de cada ataque al matriarcado de las cinco hermanas. Indignación de generaciones enteras de adultos, profesionales o rentistas, frente a ese despilfarro de bienes al sol, de rentas, títulos, bonos del tesoro, muebles, platas, a esa oleada de agua y luz en las habitaciones, de corrientes de aire que atacaban los delicados bronquios de los niños, a ese desprecio por las cotizaciones bursátiles, por las consecuencias monetarias de la guerra y por el uso de la cera en los muebles. La cera preservadora y protectora que daba brillo por encima, y que gustaba a los hombres por reflejar en ella su espíritu imperecedero. Pero ella quería el agua, quería la fiesta del agua y el dinero le resbalaba entre las manos como si de agua se tratara (Ramondino, Althénopis 1989: 24).

La abuela, con sus extravagancias y su libertad de acción tras enviudar, conquista un espacio de poder al que solo podían acceder los hombres hasta ese momento y estos, desconcertados por su carácter y sus rarezas, no lograrán someterla a los valores patriarcales que sustentan la estructura familiar, unos valores perpetuados por las propias mujeres, y que solo su actitud transgresora logrará desestabilizar.

Más allá de los contrastes que surgen a través de las descripciones físicas y emocionales, uno de los aspectos más interesantes que representan la oposición entre la madre y la abuela es la manera de actuar en la cocina ${ }^{12}$, la selección de los alimentos y las nu-

12 La cocina también refleja los desencuentros entre la abuela y su hermana, la tía Celeste, que siente una cierta envidia por su modo de vivir: "Finalmente aparecía detrás del portal, entrecerrado, todavía desconfiada, con la cara roja y untuosa de los fogones, seguida por perros y gatos, contenta de verme a mí, casi irrespetuosa en cambio con la abuela. Porque por una parte la abuela era su rival en la cocina y por otra, puesta al corriente por los patrones de sus rarezas, encontraba en la falta de respeto hacia ella una identificación o quizás una conquista en relación con el mundo de los señores" (Ramondino, Althénopis 1989: 123). 
merosas connotaciones que de ello se desprenden: "La funzione connotativa [del cibo] è quella attraverso la quale si offre una caratterizzazione dei personaggi a vari livelli (sociale, affettivo, psicologico, economico), proprio partendo dall'analisi dei cibi e della sfera alimentare" (Marchese 2013: 16). La cocina se erige como un espacio metafórico de poder femenino por ser el laboratorio de los alimentos que nutren a la familia, en un plano físico y emocional. La manera de cocinar, las cantidades y los recursos utilizados para elaborar los platos serán el reflejo de la personalidad de estas mujeres y de cómo perpetúan o rompen los valores hegemónicos a través de sus recetas. Si analizamos a los personajes a nivel socio-económico, ambas mujeres pertenecen a la clase burguesa, aunque con una diferencia sustancial: mientras que la abuela derrochó toda su riqueza "haciendo caridad con sus pobres, llenando de regalos a las hijas, las nietas, las primas, las camareras; pagando las deudas de juego del hijo y las contraídas por el cura por la compra de objetos litúrgicos" (Ramondino, Althénopis 1989: 25), un hecho por el que será reprobada por toda la familia, la madre profesa la austeridad y prefiere no gozar de sus bienes materiales por temor a perder su condición burguesa. Estas actitudes opuestas, así como las extravagancias de la abuela, encontraran su reflejo directo en la cocina. La abuela cocinaba de manera instintiva y espontánea, utilizando toda su fantasía en los fogones, como una forma de transgredir las reglas y alimentar con esa rebeldía al resto de la familia:

Amábamos su cocina más que ninguna, nunca concebida en el ahorro o con las modernas reglas higiénicas o dietéticas, sino con la fantasía. En la familia se reían de su forma de cocinar; luego las mujeres se indignaban por el abuso de las cremas y el aceite, por las ollas que había que reordenar. En cambio, los hombres sentían fastidio o por lo menos sospecha, -aquellos hombres de familias meridionales que en cada ramita de perejil piensan en una mosca, que en el temblor de una crema temen las arenas movedizas del sexo, y que durante toda la vida se les cae la baba por el modo de cocinar de la madre, únicas manos de las que poder fiarse de las cremas y las ramitas de perejil (Ramondino, Althénopis 1989: 28).

Los niños de la familia, con su mirada inocente y privada de prejuicios, son los únicos que disfrutan de sus suculentos platos, mientras que los adultos, especialmente los varones, se sienten desafiados ante sus viandas llenas de creatividad, porque son estimadas conatos de rebeldía hacia el orden patriarcal hegemónico. Así, y mientras la protagonista disfruta de las deliciosas cremas que la abuela preparaba, el padre las detesta, sin dar explicaciones sobre los motivos que le llevan a aborrecer sus comidas, y tan solo trata de persuadir al hijo varón para que también muestre su rechazo al alimento ${ }^{13}$. La comida es la única forma visible que tiene la abuela de expresar su desprecio por el sistema de valores familiar y lo manifiesta deconstru-

13 "Hacía también con gran destreza, ya que eran tiempos de gran carestía y no había ingredientes, algunas cremas fabulosas que, sin embargo, repugnaban a los demás. Sobre todo nuestro padre tenía un aire mareado, y trataba vanamente de convencer a nuestro hermano, el varón de la familia, para que le siguiera) (Ramondino, Althénopis 1989: 29). 
yendo los platos tradicionales o haciendo una mezcla de ingredientes poco al uso. Servir los platos en la mesa y observar cómo el resto de familia estaba obligada a degustarlos es una sutil forma de rebelarse a la imposición de los varones y quienes reafirmaban su poder.

Por otra parte, y cómo se describe, la madre condena su cocina porque en ella ve el reflejo de la trasgresión y la falta de moderación, algo impropio en una mujer:

El disgusto de mi madre distinto y todo él cerebral; no estaba de acuerdo con la irracionalidad de aquella manera de cocinar, por el desprecio de la proporción entre proteínas, hidratos de carbono, vitaminas, el despilfarro de dinero y, finalmente, por la poca correspondencia entre el libro de cocina y los resultados, los cuales, dado cierto tipo de plato, había que esperar similares (Ramondino, Althénopis 1989: 29).

Cuando la madre vuelve a vivir con la hija y sus hermanos, todos esos excesos y extravagancias son sustituidos por estrictas normas y "un despiadado sentido de la realidad" (Ramondino, Althénopis 1989: 56), que no dejan espacio a la imaginación o al mundo emocional que la abuela había creado. La madre, tras el matrimonio y la maternidad, se transforma en una mujer "prosaica que no creía ni en las fábulas, ni en la muerte, ni en el amor" (63), y la escritora utiliza la metáfora culinaria, como el alimento del cuerpo y del alma, para censurar el comedimiento materno y el rigor con el que lo aplicaba a todos los aspectos de su vida, elogiando de nuevo la desobediencia de la abuela:

[...] me recordaba aquella justa medida en todas las cosas que continuamente me achacaban debido a mi desmesura; y a mamá que pesaba los ingredientes antes de ponerse a amasar un dulce, por lo que todo estaba equilibrado en cantidad y sabor; mientras que, en cambio, disfrutaba con el extravío de la abuela entre los huevos y la harina; disfrutaba de la desmesura de sus dulces que navegaban entre las cremas, inundados de baños de chocolate y de azúcar quemado, de los que siempre quedaban generosas porciones tras nuestro ávido asalto [...] (Ramondino, Althénopis 1989: 141).

Por estos motivos, y tras el fallecimiento de la abuela, la cocina será un espacio significativo para la protagonista, que en ocasiones se refugiará en ella para tratar de huir de las imposiciones maternas y su artificiosa educación, que pretendía desconectarla de los elementos naturales de la vida, de su propio cuerpo, para someterla a los rígidos valores sociales. Dado que el cuerpo femenino tiene una lectura social, ya que los aspectos corpóreos tienen implicaciones en la identidad de los sujetos, y la protagonista rechaza estos valores inculcados principalmente por la madre, esta tiene dificultades para reconocerse y reconocer su cuerpo, por lo que busca en un lugar eminentemente femenino su identidad. En la cocina se relaciona con elementos naturales, como si conectase con 
la tierra ${ }^{14}$, con lo corpóreo, tocando las verduras o las legumbres. Su vivencia en la cocina le ayuda a descubrir y disfrutar de la sensorialidad de su cuerpo, que apreciará como un elemento propio y no como un "cuerpo para el otro" (Alemany Anchel y Velasco Laiseca 2008: 43), ajeno a los placeres y determinado por los factores socioculturales que lo rodean. Reconocer su cuerpo es el primer paso para establecer vínculos con el entorno en el que vive, pues este "condiciona la percepción de las experiencias mediante una serie de discursos donde el género juega un papel primordial" (Vivero Marín 2008: 79). La protagonista, que no encuentra ningún referente social o familiar que valide la vivencia actual del cuerpo femenino debido a la cantidad de imposiciones socioculturales por parte del entorno, parece buscar en la cocina un espacio en el que reconocerse y en el que, a su vez, pueda recordar a la abuela, la única mujer con la que se puede vagamente identificar.

Me dejaba llevar ociosamente y desde la mañana trasegaba en aquella cocina. Me gustaba ayudarlas a cortar las berenjenas, los calabacines, las patatas y en esos momentos mi torpe ansiedad y mi fútil integridad de adolescente se veían corrompidas por la vida y, cuando la punta de los dedos se me teñía de oscuro y sentía la piel ponerse de gallina, me parecía que por fin algo, aunque muy pequeño, me hubiera sucedido. Más aún me gustaba freír las berenjenas y los calabacines y parecía que mi vaga, débil y reiterada inconsistencia, aunque todavía informe, se concentrara y se hiciera sustancia en los pesados vapores del aceite frito; y cuando alguna gota hirviendo me salpicaba las manos, los brazos o el cuello, me parecía que por fin poseía manos, brazos y cuello. Inmersa en aquellos densos y ardientes vapores, en aquel maloliente hollín me parecía leer mi futuro como mujer e imaginaba cocinar para una gran familia futura o pretérita que dormía el último y perezoso sueño de la mañana; [...]. En cambio otras veces me gustaba lavar los platos y sumergir las manos con una laboriosa voluptuosidad en aquel agua grasienta y resbaladiza de sosa. Me gustaba sentir la grasa disolviéndose y, en aquel agua gris y maloliente, me parecía entrever todos los turbulentos secretos de la vida. Aquel era un modo

14 Más adelante, la protagonista habla de los cambios que sufre su cuerpo durante la adolescencia y habla de algo que perturba su cuerpo, a lo que llama "vida de mi vida" o "mi videcita" y, más tarde "mi Principio". Una posible lectura de "Mi Principio" es la pulsión sexual que crece y que no sabe explicar, pero logra interpretar con metáforas que aluden a la tierra. Así, en esta descripción metafórica, la protagonista, tras una especie de sueño iniciático, podría haber descubierto una parte de su cuerpo: la del placer y la masturbación. Para ello, la escritora elige imágenes cargadas de simbolismo como la rosa, la tierra o el rocío: "Cuando desperté sabía que guardaba relación con mi secreta compañía, con mi Principio. Me quedé entorpecida durante un tiempo, asaltada por una felicidad que nunca había sentido y que me mantenía anclada a la tierra: “¿por qué tengo que levantarme?, ¿adónde tengo que ir?”. Y permanecía tumbada. El siroco me hacía arder las piernas y las mejillas. Tenía las manos sumergidas en la tierra arenosa y pensaba, riendo estúpidamente: “esta es la tierra". También pensaba, "estoy sola", pero esto no me turbaba como en otras ocasiones; al contrario, me llenaba de contento. Delante de los ojos pasó un flujo de imágenes, e las que recuerdo una: la rosa. Creció sobre la tierra arenosa y árida y sobre el tallo derecho y fuerte descapulló cubierta de rocío. Era de un rosa intenso; el orgullo de tal color era justamente el de no querer oscilar hacia el blanco ni el de inclinarse hacia el rojo. Miles de arrumacos infantiles acudían a mi boca, pero los labios permanecían mudos, rechazando pronunciarlos y las manos permanecían inmóviles en la arena. Con la fuerza del deseo me veía manos de cristal, no dos, sino cien, que acariciaban la rosa con gestos de fiesta y maravilla. La llamé la Rosa Inicial” (Ramondino, Althénopis 1989: 311). 
personal de interpretar la resurrección de los muertos, ya que detrás de los vapores, las excrecencias y los sudores de la cocina, veía aparecer los semblantes de la abuela, de la que, durante aquel menstrual comienzo de la adolescencia, advertía con más fuerza su ausencia (Ramondino, Althénopis 1989: 250).

Más adelante, y tras haber tomado conciencia sobre su cuerpo, la protagonista habla de los cambios que este sufre durante la adolescencia y, en concreto, se refiere a algo que la perturba, a lo que llama "vida de mi vida" o "mi videcita" y, más tarde "mi Principio". Una posible lectura de "mi Principio" es la pulsión sexual que crece y que no sabe explicar, pero logra interpretar con metáforas que aluden a la tierra. Así, en esta descripción metafórica, la protagonista, tras una especie de sueño iniciático, podría haber descubierto una parte de su cuerpo: la del placer y la masturbación. Para ello, la escritora elige imágenes cargadas de simbolismo como la rosa, la tierra o el rocío:

Cuando desperté sabía que guardaba relación con mi secreta compañía, con mi Principio. Me quedé entorpecida durante un tiempo, asaltada por una felicidad que nunca había sentido y que me mantenía anclada a la tierra: "¿por qué tengo que levantarme?, ¿adónde tengo que ir?”. Y permanecía tumbada. El siroco me hacía arder las piernas y las mejillas. Tenía las manos sumergidas en la tierra arenosa y pensaba, riendo estúpidamente: "esta es la tierra". También pensaba, "estoy sola", pero esto no me turbaba como en otras ocasiones; al contrario, me llenaba de contento. Delante de los ojos pasó un flujo de imágenes, e las que recuerdo una: la rosa. Creció sobre la tierra arenosa y árida y sobre el tallo derecho y fuerte descapulló cubierta de rocío. Era de un rosa intenso; el orgullo de tal color era justamente el de no querer oscilar hacia el blanco ni el de inclinarse hacia el rojo. Miles de arrumacos infantiles acudían a mi boca, pero los labios permanecían mudos, rechazando pronunciarlos y las manos permanecían inmóviles en la arena. Con la fuerza del deseo me veía manos de cristal, no dos, sino cien, que acariciaban la rosa con gestos de fiesta y maravilla. La llamé la Rosa Inicial (Ramondino, Althénopis 1989: 311).

La protagonista logra reconocerse como mujer tras una incesante búsqueda de la subjetividad femenina, pero su proceso identitario solo logrará completarse tras resolver el conflicto con la madre y reconocerla como mujer.

\section{Resolución del conflicto maternofilial}

A través de las escenas cotidianas, entre ellas las culinarias, Ramodino detalla los territorios emotivos que caracterizan la relación entre la madre y la madre de la madre, y a su vez, de estas con la protagonista. Siguiendo el estudio de Cristina Faccincani Gorreri (2007), la representación trigeneracional sirve para "[...] rintracciare il senso di tutto ciò che la figlia si ritrova a incarnare, sia come eredità vivente di quella relazione, sia come vincolo alla riparazione delle falle di quella relazione, ciò che paradossalmente la pone in posizione di madre della propria madre" (Faccincani Gorreri 2007: 6). 
La protagonista describe su relación con la abuela y con la madre, pero esta última aparece con una doble identidad: como madre y como hija al mismo tiempo. En la narración se reconstruyen los conflictos que experimentó la madre con la abuela, y esto ayudará a la protagonista a comprender y superar los obstáculos que caracterizan su vínculo con la madre ${ }^{15}$. La hija se ve obligada a aceptar esa alteridad materna, y será la propia madre quien se revele ante la hija como niña y como mujer. Respecto al primer aspecto, en el último capítulo del libro se describe la muerte de la madre y, significativamente, comienza con la descripción de la madre como una niña: "La niña que había sido su madre renacía en los últimos días de su vida. Porque cada uno de nosotros tiene a otro enterrado que aguarda su día con un chisporroteo sumergido" (Ramondino, Althénopis 1989: 363). Más adelante, y en lo concerniente al segundo aspecto, antes de su muerte, la madre "sin pudor y con insistencia en los primeros días se tocaba el pubis" y, tras ser reprobada por las otras mujeres de la familia, respondía “isoy una niña, soy una niña!” (Ramondino, Althénopis 1989: 367). La protagonista interpreta aquel gesto como una cesión de un poder generativo (Giorgio 2002: 128) y como una manera de reclamar que la maternidad y la sexualidad no pueden ser excluyentes, ya que la sexualidad es esencial para la identidad femenina. Así, la protagonista logrará concluir su proceso identitario tras reconocer a la madre como un sujeto autónomo y sexual:

La donna-madre che si era messa tra parentesi, costretta dai ruoli e dalle vicissitudini della sua vita a corrodere fino in fondo la sua femminilità identitaria, la reclama perentoriamente, recriminando, al contempo, la sua infanzia tradita e additando i suoi diritti soggettivi di bambina e di donna (Chemotti 2009: 240).

La muerte de la madre supone la liberación de la hija, quien puede ver la posibilidad que se abre de "[...]levantar la prohibición y fecundarla, para que vieran de nuevo la luz otras criaturas nacidas de mujer" (Ramondino, Althénopis 1989: 367), vislumbrando un futuro más esperanzador para las mujeres. La novela, por tanto, se concluye con la esperanza de poder construir nuevos vínculos afectivos entre madres e hijas fuera de los cánones patriarcales, que eliminan cualquier aspecto de la sexualidad femenina y convierten a la madre en un ser reproductor, "più vicina all'animalità che alla femminilità" (Chemotti 2009: 22). Ello conlleva la aceptación de los sujetos femeninos implicados, los cuales, tras superar sus diferencias, lograrán reestablecer la armonía perdida.

15 La estudiosa analiza la dificultad que entraña el ver la alteridad de la madre pero, al mismo tiempo, es necesaria para poder reparar las lagunas y las carencias en la relación: "Questa capacità di sguardo sulla propria madre come figlia (in un'altra relazione e in un altro tempo) richiede l'accettazione, dentro il legame affettivo, di una componente di alterità radicale, di una componente di estraneità nel legame affettivo che è molto difficile da raggiungere perché implica una traversia emotiva che comporta la rinuncia a vedere e volere la madre come qualcuno che nasce con me in una sorta di con-generazione, a cui appartengo e che mi appartiene, e che al massimo devo condividere in una spartizione con qualcun altro" (Faccincani Gorreri 2007: 6-7). 


\section{BIBLIOGRAFÍA}

ALEMANY ANCHEL, María José; VELASCO LAISECA, Javier (2008): “Género, imagen y representación del cuerpo". Index Enfermeria. Vol. 17: 39- 43.

BENEDETTI, Laura (2007): The tigress in the snow. Motherhood and Literature in Twentieth-Century Italy. Toronto: University of Toronto Press.

BRUSA, Luisella (2004): Mi vedevo riflessa nel suo specchio. Psicoanalisi del rapporto tra madre e figlia. Milano: Franco Angeli.

CERRI, Chiara (2010): "La subjetividad de género. El sujeto sexuado entre individualidad y colectividad". Gazeta de Antropología. 26: 1-12.

CHEMOTTI, Saveria (2009): L'inchiostro bianco. Madri e figlie nella narrativa italiana contemporanea. Padova: Il Poligrafo.

DI ROSA, Rossella (2016): Itinerari nomadici ed ecologici nella narrativa di Anna Maria Ortese, Elsa Morante e Fabrizia Ramondino. New Jersey: Ph.D

FACCINCANI GORRERI, Cristina (2007): "Paradossi del materno", Diotima (ed.). L'ombra della madre. Napoli: Liguori editore, 5-16.

GIORGIO, Adalgisa (2002): "The Passion for the Mother: Conflicts and Idealisations in Contemporary Italian Narrative by Women", Adalgisa Giorgio (ed.). Writing Mothers and Daughters. Renegotiating the Mother in Western European Narratives by Women. New York-Oxford: Berghahn, 119- 154.

(2014): "Napoli e le scrittrici "napoletane" in Inghilterra. Alcune riflessioni teorico-metodologiche, a partire da Fabrizia Ramondino", Rita Nicolì (ed.). Letteratura meridionale. Contesti nazionali e sovranazionali. Atti del Convegno di Studi ADI Puglia e Basilicata (Lecce, 17-19 maggio 2012). Roma: ADI, 34-44.

LAZZARO-WEIS, Carol (1993): From margins to mainstream. Feminism and Fictional Modes in Italian Women's Writing 1968-1990. Pennsylvania: The Pennsylvania State University Press.

MARCHESE, Dora (2013): Il gusto della letteratura. La dimensione gastronomico-alimentare negli scrittori italiani moderni e contemporanei. Roma: Carocci editore.

MAROTTI, Maria Ornella (1996): “Ethnic Matriarchy: Fabrizia Ramondino's Neapolitan World", Maria Ornella Marotti (ed.). Italian Women Writers from the Renaissance to the Present. Revising the Canon. Pennsylvania: The Pennsylvania State University Press, 173- 186.

MURARO, Luisa (1992): "L'orientamento della riconoscenza", Diotima (ed.) Il cielo stellato dentro di noi. L'ordine simbolico della madre. Milano: Tartaruga edizioni, 9-19.

RAMONDINO, Fabrizia (1989): Althénopis. Madrid: Alfaguara.

USHER, Jonathan (1993): "The Muse of Memory", Zygmunt G. Baranski; Lino Pertile (ed.). The New Italian Novel. Edinburgh: Edinburgh University Press, 166- 183.

VIVERO MARÍN, Cándida Elizabeth (2008): "El cuerpo como paradigma teórico en literatura". La Ventana. Vol. 3, No. 28: 59-83.

WOOD, Sharon (1995): Italian Women's Writing, 1860-1994. New Jersey: The Athlone Press. 


\section{PERFIL ACADÉMICO-PROFESIONAL}

María Reyes Ferrer es licenciada en Filología Inglesa por la Universidad de Murcia y Filología Italiana por la Universidad de Salamanca. Es doctora por la Universidad de Sevilla con una tesis sobre la novela histórica italiana femenina. Actualmente imparte clases de lengua y cultura italiana en el Departamento de Filología Francesa, Románica, Italiana y Árabe de la Universidad de Murcia. Forma parte del grupo de investigación Escritoras y Escrituras (Hum 753) y sus investigaciones se centran en la narrativa femenina italiana y los estudios de género.

Fecha de recepción: 10/05/2019

Fecha de aceptación: 26/06/2019 